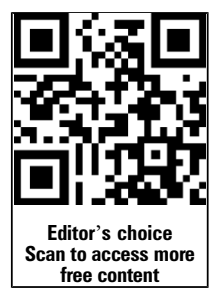

${ }^{1}$ Centre for Human and Applied Physiology, School of Medicine, University of Wollongong, Wollongong, New South Wales, Australia ${ }^{2}$ Performance Department, St. George Illawarra Dragons Rugby League Football Club, Wollongong, New South Wales, Australia

${ }^{3}$ School of Exercise Science, Australian Catholic University, Brisbane, Queensland, Australia

${ }^{4}$ School of Human Movement Studies, University of Queensland, Brisbane, Queensland, Australia ${ }^{5}$ School of Psychology, University of Wollongong, Wollongong, New South Wales, Australia

\section{Correspondence to} Billy T Hulin, Centre for Human and Applied Physiology, School of Medicine, University of Wollongong, Wollongong, NSW 2522, Australia; billyhulin@hotmail.com

Accepted 3 October 2015 Published Online First 28 October 2015

\title{
The acute:chronic workload ratio predicts injury: high chronic workload may decrease injury risk in elite rugby league players
}

\author{
Billy T Hulin, ${ }^{1,2}$ Tim J Gabbett, ${ }^{3,4}$ Daniel W Lawson, ${ }^{2}$ Peter Caputi, ${ }^{5}$ \\ John A Sampson ${ }^{1}$
}

\begin{abstract}
Aim Investigate whether acute workload (1 week total distance) and chronic workload (4-week average acute workload) predict injury in elite rugby league players.

Methods Data were collected from 53 elite players over two rugby league seasons. The 'acute:chronic workload ratio' was calculated by dividing acute workload by chronic workload. A value of greater than 1 represented an acute workload greater than chronic workload. All workload data were classified into discrete ranges by z-scores.

Results Compared with all other ratios, a very-high acute:chronic workload ratio $(\geq 2.11)$ demonstrated the greatest risk of injury in the current week (16.7\% injury risk) and subsequent week (11.8\% injury risk). High chronic workload (>16 $095 \mathrm{~m}$ ) combined with a veryhigh 2-week average acute:chronic workload ratio $(\geq 1.54)$ was associated with the greatest risk of injury (28.6\% injury risk). High chronic workload combined with a moderate workload ratio (1.02-1.18) had a smaller risk of injury than low chronic workload combined with several workload ratios (relative risk range from 0.3 to $0.7 \times 1 \div 1.4$ to 4.4 ; likelihood range $=88-94 \%$, likely). Considering acute and chronic workloads in isolation (ie, not as ratios) did not consistently predict injury risk.
\end{abstract}

Conclusions Higher workloads can have either positive or negative influences on injury risk in elite rugby league players. Specifically, compared with players who have a low chronic workload, players with a high chronic workload are more resistant to injury with moderate-low through moderate-high (0.85-1.35) acute:chronic workload ratios and less resistant to injury when subjected to 'spikes' in acute workload, that is, very-high acute:chronic workload ratios $\sim 1.5$.

\section{INTRODUCTION}

Injuries commonly occur in team sports ${ }^{1-4}$ and negatively influence team success in domestic ${ }^{5}$ and continental ${ }^{7}$ competitions. High training and match-play workloads increase injury likelihood in team sports. ${ }^{8}{ }^{9}$ However, physical attributes such as higher aerobic capacity, prolonged high-intensity running ability, and greater body mass index, improve with increases in workload ${ }^{10-13}$ and decrease injury likelihood. ${ }^{14-16}$ Consequently, the optimal workload that improves fitness, without increasing the likelihood of injury is of great importance to coaches and clinicians. ${ }^{17}$

Workload-injury investigations in team sports typically quantify workload in absolute terms (eg, the workload performed in a week vs injury). ${ }^{8} 918$
However, workload-performance investigations have examined absolute workload performed in 1 week (referred to as acute workload) relative to 4-week chronic workload (ie, 4-week average acute workload). ${ }^{19-21}$ The logic behind this comparison of workloads is the provision of a workload index, which provides an indication of whether the athlete's recent acute workload is greater, less than or equal to the workload that the athlete has been prepared for during the preceding chronic period. We refer to this method as the acute:chronic workload ratio.

Using the acute:chronic workload ratio concept, we demonstrated that the risk of cricket fast bowlers sustaining an injury increased threefold when acute bowling workloads were double chronic bowling workloads (ie, an acute:chronic workload ratio $\geq 2) .{ }^{22}$ Also, higher chronic workload protected against injury. However, the physical demands of cricket differ from many high-intensity, intermittent football codes. ${ }^{23}$ The acute:chronic workload ratio, which compares the size of acute workload relative to chronic workload has not been used to investigate the workload-injury relationship in a team sport other than cricket. Furthermore, no study has investigated the influence of changes in acute workload when players have been exposed to either high or low chronic workloads.

Global positioning systems (GPS) data provides a major advancement in the ability of scientists, coaches and clinicians to monitor individual athlete's workloads even in the team sport setting. ${ }^{24-31}$ To our knowledge, no research has investigated if the comparison of acute and chronic workloads derived from GPS is associated with injury in either the current week, subsequent week, or as an average over 2 weeks, in elite team sport athletes. 1832 Therefore, we investigated whether distance covered, measured by GPS and calculated as an acute:chronic workload ratio predicted injury in elite rugby league players.

\section{METHODS}

\section{Participants}

Fifty-three players (mean \pm SD age, $23.4 \pm 3.5$ years) from one elite rugby league club participated in this study over two Australian National Rugby League seasons. Of the two seasons, 20 (38\%) participants competed in both seasons and 33 (62\%) participants competed in one season-equating to a total of 73 individual seasons of rugby league. Each season consisted of a 13-week pre-season period 
followed by 27 weeks of competition. All participants provided written consent and received a clear explanation of the study. All experimental procedures were approved by the Institutional Review Board for Human Investigation.

\section{Quantifying workload}

Workload was defined as absolute total distance (m) covered during all field training sessions and matches and was measured via GPS (GPSports, SPI-HPU $5 \mathrm{~Hz}$ (interpolated $15 \mathrm{~Hz}$ ), Canberra, Australia). The GPS equipment used in this study is accurate and reliable for measuring total distance covered. ${ }^{33} 34$ This equipment presents challenges when measuring accelerations, decelerations, ${ }^{35}$ high-speed running ${ }^{34} 36$ and collisions. ${ }^{37}$ Therefore, total distance was the only variable included in this study. $^{38}$

Our analysis included all field training sessions and matches throughout the 2013 and 2014 seasons. A total of 8177 individual files consisting of 6777 training session files and 1400 match files were used.

\section{Definition of injury}

Injury records were updated and maintained by the club's senior physiotherapist. An injury was defined as any time-loss injury that resulted in a player being unable to complete full training or missing match time. ${ }^{39}$ Thus, our definition of injury included both 'acute' and 'overuse' injuries.

\section{Data analysis}

Data were categorised into weekly blocks from Monday to Sunday. One-week total distance covered represented acute workload. Chronic workload was calculated as the 4-week rolling average acute workload. Skewness and kurtosis indices were explored using SPSS and data demonstrated normal distribution. The acute:chronic workload ratio was calculated by dividing the acute workload by the chronic workload-providing the relative size of acute workload compared with chronic workload. A value of greater than 1 represents an acute workload greater than chronic workload and vice versa.

Workload classifications consisting of very-low through veryhigh were created according to z-scores. ${ }^{40} 41$ These classifications are displayed in table 1 . Absolute workload and relative workload ratios are different variables and may display a different amount of variation. This could explain the asymmetrical z-scores for very-low through very-high acute:chronic workload ratios.

Training weeks in which players performed a chronic workload below a z-score of -2 (very-low) were removed from the analysis of acute:chronic workload ratios. ${ }^{22}$ This removal

Table 1 Workload classifications and boundaries for: (A) acute workloads, (B) chronic workloads, (C) acute:chronic workload ratios overall, and (D) acute:chronic workload ratios combined with low (<16 $095 \mathrm{~m})$, and high (>16 $095 \mathrm{~m})$ chronic workloads

\begin{tabular}{|c|c|c|c|}
\hline (A) Acute workload & z-Score & Current and Subsequent week (m) & Two-week average $(\mathrm{m})$ \\
\hline Very-low & $\leq-2.00$ & $\leq 3268$ & $\leq 5020$ \\
\hline Low & -1.99 to -1.00 & 3269-9624 & $5021-10351$ \\
\hline Moderate-low & -0.99 to -0.01 & $9625-16000$ & $10352-15668$ \\
\hline Moderate-high & 0.00 to 0.99 & $16001-22364$ & $15669-20966$ \\
\hline High & 1.00 to 1.99 & $22365-28797$ & $20967-26265$ \\
\hline Very-high & $\geq 2.00$ & $\geq 28798$ & $\geq 26266$ \\
\hline \multicolumn{4}{|l|}{ (B) Chronic workload } \\
\hline Very-low & $\leq-2.00$ & $\leq 6955$ & $\leq 6675$ \\
\hline Low & -1.99 to -1.00 & $6956-11343$ & $6676-11074$ \\
\hline Moderate-low & -0.99 to -0.01 & $11343-15729$ & $11075-15526$ \\
\hline Moderate-high & 0.00 to 0.99 & $15730-20116$ & $15527-19995$ \\
\hline High & 1.00 to 1.99 & $20117-24503$ & $19996-24449$ \\
\hline Very-high & $\geq 2.00$ & $\geq 24504$ & $\geq 24450$ \\
\hline (C) Acute:chronic workload ratio & & Current and Subsequent week & Two-week average \\
\hline Very-low & $\leq-2.00$ & $\leq 0.30$ & $\leq 0.45$ \\
\hline Low & -1.99 to -1.00 & $0.31-0.66$ & $0.46-0.74$ \\
\hline Moderate-low & -0.99 to -0.01 & $0.67-1.02$ & $0.75-1.01$ \\
\hline Moderate & 0.00 to 0.99 & $1.03-1.38$ & $1.02-1.30$ \\
\hline Moderate-high & 1.00 to 1.99 & $1.39-1.74$ & $1.31-1.58$ \\
\hline High & 2.00 to 2.99 & $1.75-2.10$ & $1.59-1.87$ \\
\hline Very-high & $\geq 3.00$ & $\geq 2.11$ & $\geq 1.88$ \\
\hline (D) Acute:chronic workload ratio & & Combined with low chronic workload & Combined with high chronic workload \\
\hline Very-low & $\leq-2.00$ & $\leq 0.30$ & $\leq 0.66$ \\
\hline Low & -1.99 to -1.00 & $0.31-0.66$ & $0.67-0.84$ \\
\hline Moderate-low & -0.99 to -0.01 & $0.67-1.02$ & $0.85-1.01$ \\
\hline Moderate & 0.00 to 0.99 & $1.03-1.37$ & $1.02-1.18$ \\
\hline Moderate-high & 1.00 to 1.99 & $1.38-1.74$ & $1.19-1.35$ \\
\hline High & 2.00 to 2.99 & $1.75-2.16$ & $1.36-1.53$ \\
\hline Very-high & $\geq 3.00$ & $\geq 2.17$ & $\geq 1.54$ \\
\hline
\end{tabular}


equated to $3.8 \%$ of the data set (86 of 2292 individual training weeks). This was performed so that a small increase in acute workload at very-low chronic workload would not be considered. That is, a player who had been subjected to an acute workload of $3000 \mathrm{~m}$, whilst having a chronic workload of $1000 \mathrm{~m}$, would have a very-low $(2000 \mathrm{~m})$ absolute increase in workload but this would represent a very-high acute:chronic workload ratio. ${ }^{22}$ These very low workloads remained in the data set for the independent comparison of injury with absolute workloads.

The second aim of the present study was to investigate injury risk relative to the acute:chronic workload ratio when chronic workload is high, and when chronic workload is low. As such, chronic workloads were dichotomised by the median score $(16095 \mathrm{~m})$ and injury-workload relationships between acute: chronic workload ratios combined with high, and low chronic workloads were calculated.

\section{Statistical analysis}

The risk of injury $\pm 90 \%$ CI was calculated for the week that the workload occurred (current week), the following week (subsequent week), and for the average workload over the current and previous week (2-week average). Injury risks were calculated as the number of injuries sustained relative to the number of exposures to each workload classification. ${ }^{22} 38$ Null-hypothesis testing was conducted using a binary logistic regression model with injury/no injury as the dependent variable. Acute workload, chronic workload, and acute:chronic workload ratios were independently modelled as predictor variables. Relative risk $(\mathrm{RR}) \times / \div 90 \%$ CI were calculated to determine which workload variables increased $(R R>1)$ or decreased $(R R<1)$ the risk of injury. ${ }^{38}$ Owing to the inability of RR to provide $\pm 90 \% \mathrm{CI}$, the square root of (upper $\mathrm{CI} /$ lower $\mathrm{CI}$ ) provided a $\times / \div 90 \% \mathrm{CI}^{4}{ }^{42}$

Results of clinical and practical significance can be overlooked due to non-significant $(p>0.05)$ null-hypothesis tests, which fail to adequately deal with the real-world importance of an effect. ${ }^{43}{ }^{44}$ As such, the $\mathrm{p}$ value derived from binary logistic regression and the value of the RR between groups were used to calculate the probabilities that the true effect was harmful, trivial and beneficial. ${ }^{42}$ These values were reported in quantitative and qualitative terms according to the following: $\geq 5 \%$, unlikely; $\geq 25 \%$, possibly; $\geq 75 \%$, likely; $\geq 95 \%$, very likely. ${ }^{43} 44$ Practical significance occurred when the probability that the true effect was either harmful or beneficial was $\geq 75 \%$, likely. ${ }^{44}$

\section{RESULTS}

A total of 205 injuries $(20.2 / 1000 \mathrm{~h})$ were recorded. The most common sites of injury were the thigh (23.4\%), knee (13.2\%), and ankle (11.7\%).

\section{Acute, and chronic workloads}

In the current week, a very-high acute workload ( $\geq 28798 \mathrm{~m}$ ) was associated with an increased risk of injury, compared with all other acute workloads (RR range from 1.9 to $13.9 \times / \div 1.9$ to 2.2; likelihood range $=86-98 \%$, likely-very likely), table 2 . There were no differences in injury risk among any chronic workload categories (RR range from 0.6 to $1.3 \times / \div 1.0$ to 15.8 ; likelihood range $=16-63 \%$, unlikely-possibly), table 3 .

\section{Acute:chronic workload ratio}

In the current week, a very-high acute:chronic workload ratio $(\geq 2.11)$ was associated with an injury risk that was: (1) 6.9 times greater than a very-low ratio of $\leq 0.30(\mathrm{RR}=6.9 \times / \div 1.7$; likelihood $=98 \%$, very likely), (2) 3.4 times greater than a low ratio of $0.31-0.66(\mathrm{RR}=3.4 \times / \div 2.0$; likelihood $=97 \%$, very
Table 2 Relationships between acute workload and the risk of injury $( \pm 90 \% \mathrm{Cl})$ during the current week, subsequent week, and with 2-week average acute workloads

\begin{tabular}{|c|c|c|c|}
\hline \multicolumn{4}{|c|}{ Risk of injury $(\%) \pm 90 \% \mathrm{Cl}$} \\
\hline Acute workload & Current week & Subsequent week & Two-week average \\
\hline Very-low & $1.5 \pm 2.4^{*}$ & $8.0 \pm 5.2$ & $2.2 \pm 2.5 \dagger$ \\
\hline Low & $6.0 \pm 2.2$ & $10.3 \pm 2.8$ & $5.8 \pm 2.3 \ddagger$ \\
\hline Moderate-low & $9.9 \pm 1.9$ & $6.9 \pm 1.7$ & $8.8 \pm 1.8$ \\
\hline Moderate-high & $8.4 \pm 1.5$ & $11.0 \pm 1.8$ & $9.2 \pm 1.6$ \\
\hline High & $8.0 \pm 2.3$ & $6.9 \pm 2.2 \S$ & $8.0 \pm 2.4$ \\
\hline Very-high & $18.8 \pm 16.19$ & $0.0 \pm 0.0$ & $6.3 \pm 10.0$ \\
\hline \multicolumn{4}{|c|}{$\begin{array}{l}\text { *Very likely }(\geq 95 \%) \text { decreased risk of injury than moderate-low through very-high in } \\
\text { the current week. } \\
\text { tLikely }(\geq 75 \%) \text { decreased risk of injury than 2-week average categories moderate-low } \\
\text { through very-high. } \\
\text { fLikely }(\geq 75 \%) \text { decreased risk of injury than 2-week average acute workload } \\
\text { categories moderate-low and moderate-high. } \\
\text { §Very likely }(\geq 95 \%) \text { and likely ( } \geq 75 \%) \text { decreased risk of injury in the subsequent } \\
\text { week compared with moderate-high and low. } \\
\text { IVery likely ( } \geq 95 \%) \text { greater injury risk in the current week than very-low and low, } \\
\text { and likely }(\geq 75 \%) \text { greater injury risk in the current week than moderate-low through } \\
\text { high. }\end{array}$} \\
\hline
\end{tabular}

likely), (3) 2.3 times greater than a moderate ratio of 1.03-1.38 $(\mathrm{RR}=2.3 \times / \div 3.4$; likelihood $=91 \%$, likely), and (4) double that of a high ratio of $1.75-2.10 \quad(\mathrm{RR}=2.0 \times / \div 17.2$; likelihood $=77 \%$, likely), table 4 .

A very-high 2 -week average acute:chronic workload ratio $(\geq 1.88)$ was associated with a risk of injury that was: (1) 2.2 times greater than a low ratio of $0.46-0.74(\mathrm{RR}=2.2 \times / \div 4.9$; likelihood $=87 \%$, likely), (2) 1.9 times greater than a moderatelow ratio of $0.75-1.01 \quad(\mathrm{RR}=1.9 \times / \div 5.5$; likelihood $=83 \%$, likely), and (3) 2.4 times greater than a moderate ratio of $1.02-$ $1.30(\mathrm{RR}=2.4 \times / \div 3.0$; likelihood $=92 \%$, likely $)$, table 4 . In the subsequent week, a very-high acute:chronic workload ratio demonstrated a 10 -fold increase in injury risk compared with a very-low ratio $(\mathrm{RR}=9.8 \times 1 \div 3.6$; likelihood $=97 \%$, very likely $)$, table 4.

A high chronic workload (>16 $095 \mathrm{~m}$ ) combined with a veryhigh two-week average acute:chronic workload ratio $(\geq 1.54)$ was associated with a greater risk of injury than a high chronic workload combined with the following workload ratios: low $(0.67-0.84 \quad(\mathrm{RR}=3.0 \times / \div 4.3$; $\quad$ likelihood $=92 \%$, likely $)$, moderate-low $(0.85-1.02 \quad(\mathrm{RR}=3.8 \times / \div 2.3$; likelihood $=96 \%$, very likely)), moderate $(1.02-1.18 \quad(\mathrm{RR}=4.6 \times / \div 1.8$; likelihood $=98 \%$, very likely)), moderate-high (1.19-1.35

Table 3 Relationships between chronic workload and the risk of injury $( \pm 90 \% \mathrm{Cl})$ during the current week, subsequent week, and with 2-week average chronic workloads

Risk of injury $(\%) \pm 90 \% \mathrm{Cl}$

\begin{tabular}{lcll}
\hline $\begin{array}{l}\text { Chronic } \\
\text { workload }\end{array}$ & $\begin{array}{l}\text { Current } \\
\text { week }\end{array}$ & $\begin{array}{l}\text { Subsequent } \\
\text { week }\end{array}$ & $\begin{array}{l}\text { Two-week } \\
\text { average }\end{array}$ \\
\hline Very-low & $4.7 \pm 3.7$ & $8.9 \pm 5.3$ & $6.6 \pm 4.7$ \\
Low & $8.6 \pm 3.2$ & $8.8 \pm 3.3$ & $8.1 \pm 3.1$ \\
Moderate-low & $10.8 \pm 1.9$ & $9.2 \pm 1.8$ & $9.4 \pm 1.8$ \\
Moderate-high & $7.8 \pm 1.6$ & $8.7 \pm 1.7$ & $8.7 \pm 1.6$ \\
High & $8.5 \pm 2.6$ & $7.4 \pm 2.4$ & $8.5 \pm 2.5$ \\
Very-high & $0.0 \pm 0.0$ & $9.1 \pm 14.3$ & $0.0 \pm 0.0$ \\
\hline
\end{tabular}


Table 4 Relationships between acute:chronic workload ratios and the risk of injury $( \pm 90 \% \mathrm{Cl})$ in the current and subsequent weeks, and with 2-week average acute:chronic workload ratios

\begin{tabular}{|c|c|c|c|}
\hline \multicolumn{4}{|c|}{ Risk of injury $(\%) \pm 90 \% \mathrm{Cl}$} \\
\hline $\begin{array}{l}\text { Acute:chronic } \\
\text { workload ratio }\end{array}$ & $\begin{array}{l}\text { Current } \\
\text { week }\end{array}$ & $\begin{array}{l}\text { Subsequent } \\
\text { week }\end{array}$ & $\begin{array}{l}\text { Two-week } \\
\text { average }\end{array}$ \\
\hline Very-low & $2.4 \pm 2.8^{*}$ & $1.2 \pm 2.0^{*}$ & $0.0 \pm 0.0$ \\
\hline Low & $5.0 \pm 2.5$ & $8.9 \pm 3.4$ & $7.6 \pm 3.1$ \\
\hline Moderate-low & $10.2 \pm 1.9$ & $7.8 \pm 1.6$ & $8.9 \pm 1.6$ \\
\hline Moderate & $7.2 \pm 1.5$ & $7.8 \pm 1.6$ & $6.9 \pm 1.6$ \\
\hline Moderate-high & $10.9 \pm 3.6$ & $10.5 \pm 3.7$ & $13.0 \pm 4.3 \dagger$ \\
\hline High & $8.3 \pm 7.6$ & $8.1 \pm 7.4$ & $11.8 \pm 7.4 \ddagger$ \\
\hline Very-high & $16.7 \pm 14.4 \S$ & $11.8 \pm 12.9$ & $16.7 \pm 14.49$ \\
\hline \multicolumn{4}{|c|}{ 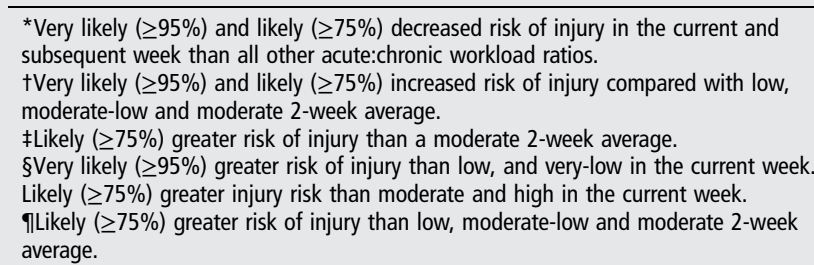 } \\
\hline
\end{tabular}

$(\mathrm{RR}=4.0 \times / \div 2.6$; likelihood $=96 \%$, likely)), and high (1.36$1.53(\mathrm{RR}=2.4 \times / \div 16.3$; likelihood $=82 \%$, likely)), table 5 .

Table 6 displays the differences in injury risk among acute: chronic workload ratios combined with high chronic workloads, and low chronic workloads.

A low chronic workload ( $<16095 \mathrm{~m})$ combined with a veryhigh two-week average acute:chronic workload ratio $(\geq 2.17)$ was associated with greater injury risks than a low chronic workload combined with the following workload ratios: low $(0.31-0.66 \quad(\mathrm{RR}=2.3 \times / \div 9.8 ; \quad$ likelihood $=84 \%$, likely $)$, moderate-low $(0.67-1.02 \quad(\mathrm{RR}=1.8 \times / \div 13.5$; likelihood $=75 \%$, likely)), moderate $(1.03-1.37 \quad(\mathrm{RR}=2.0 \times / \div 11.7$; likelihood $=79 \%$, likely)), and high $(1.75-2.16(\mathrm{RR}=3.1 \times / \div 55.5$; likelihood $=81 \%$, likely)), table 5 .

\section{DISCUSSION}

In this first study to investigate injury risk relative to the comparison of GPS derived acute and chronic workloads, we found

Table 5 Relationships among risk of injury $( \pm 90 \% \mathrm{Cl})$ and 2-week average acute:chronic workload ratios combined with low (<16 $095 \mathrm{~m}$ ) chronic workload, and high (>16 $095 \mathrm{~m}$ ) chronic workload

\begin{tabular}{lcc}
\hline \multicolumn{2}{l}{ Risk of injury $(\%) \pm 90 \% \mathrm{Cl}$} \\
\hline $\begin{array}{l}\text { Acute:chronic } \\
\text { workload ratio }\end{array}$ & $\begin{array}{l}\text { Combined with low } \\
\text { chronic workload }\end{array}$ & $\begin{array}{l}\text { Combined with high } \\
\text { chronic workload }\end{array}$ \\
\hline Very-low & $0.0 \pm 0.0$ & $0.0 \pm 0.0$ \\
Low & $7.8 \pm 4.1$ & $9.6 \pm 4.1$ \\
Moderate-low & $10.0 \pm 2.5$ & $7.5 \pm 2.2$ \\
Moderate & $9.3 \pm 2.6$ & $6.2 \pm 2.2$ \\
Moderate-high & $11.0 \pm 4.9$ & $7.1 \pm 4.0$ \\
High & $5.9 \pm 7.3$ & $12.0 \pm 10.7$ \\
Very-high & $18.2 \pm 14.9^{*}$ & $28.6 \pm 18.1 \dagger$ \\
\hline
\end{tabular}

*Likely ( $\geq 75 \%)$ greater risk of injury than a low chronic workload combined with a low, moderate-low, moderate, and high.

tVery likely $(\geq 95 \%)$ greater risk of injury than high chronic workload combined with moderate-low, moderate, and moderate-high. that a ratio of acute and chronic workloads predicted injury in elite rugby league players. This ratio indicates how the player's recent acute workload compares with the work completed during the preceding chronic period. We refer to this model as the acute:chronic workload ratio.

The value of our model is represented firstly by a very-high acute:chronic workload ratio demonstrating a greater risk of injury than all other workload ratios in the current week, subsequent week, and 2-week average. Second, the relationships between injury risk and acute, and chronic workloads in isolation were less consistent. For example, a very high acute workload was associated with an increased injury risk in the current week, yet no injuries were sustained in the subsequent week, and no injury-workload relationships were observed between a very-high 2 -week average acute workload and moderate-low to high 2-week average acute workloads. Furthermore, no injuryworkload relationships were found among any isolated chronic workload categories. Collectively these findings demonstrate that the acute:chronic workload ratio is a greater predictor of injury than either acute or chronic workload in isolation.

The workload-injury paradox: higher chronic workload protects against injury when acute workload is similar to chronic workload.

A novel finding of this study was that a high chronic workload combined with moderate, and moderate-high workload ratios had a smaller risk of injury than a low chronic workload combined with several acute:chronic workload ratios. Others have demonstrated that rugby league players with greater aerobic capacity $^{14}$ and prolonged high-intensity running ability ${ }^{15}$ have a decreased risk of injury. Potentially, players in the current study who achieved a higher chronic workload may have improved the physical attributes associated with decreased injury risk. Additionally, coaches and clinicians perceive excessive fatigue, and low levels of fitness to be important factors that increase injury risk in team sport athletes; ${ }^{17}$ higher levels of fitness reduce post-match neuromuscular fatigue in rugby league players. $^{26}$ Furthermore, Banister et $a l^{19-21}$ originally reported chronic and acute workloads as estimates of the relative comparison between fitness and fatigue. These authors did this by expressing 'fatigue' as the athlete's acute workload, whereas 'fitness' was expressed as chronic workload. ${ }^{19-21}$ When considering our findings, players who were training at a moderate acute:chronic workload ratio had an acute workload (ie, 'fatigue') similar in size to their chronic workload (ie, 'fitness'). Therefore, it may be expected that a moderate acute:chronic workload ratio combined with a high chronic workload (ie, high 'fitness') was associated with a smaller risk of injury than a moderate acute:chronic workload ratio combined with a low chronic workload (ie, low 'fitness').

The greatest risk of injury in this study was displayed when a high chronic workload was combined with a very-high acute: chronic workload ratio. Collectively, our findings highlight that compared with players that have a low chronic workload, players with a high chronic workload are: (1) more resistant to injury with moderate-low to moderate-high acute:chronic workload ratios and (2) less resistant to injury when exposed to large spikes in workload, that is, very-high acute:chronic workload ratios $\sim 1.5$.

Our results are consistent with findings from cricket. ${ }^{22}$ In the present study, when players were subjected to a workload (ie, acute workload) that was classified as $\sim$ twofold greater than the workload in which they were accustomed (ie, chronic workload), up to a 10-fold increase in the risk of injury occurred. These findings may seem intuitive and unsurprising to 


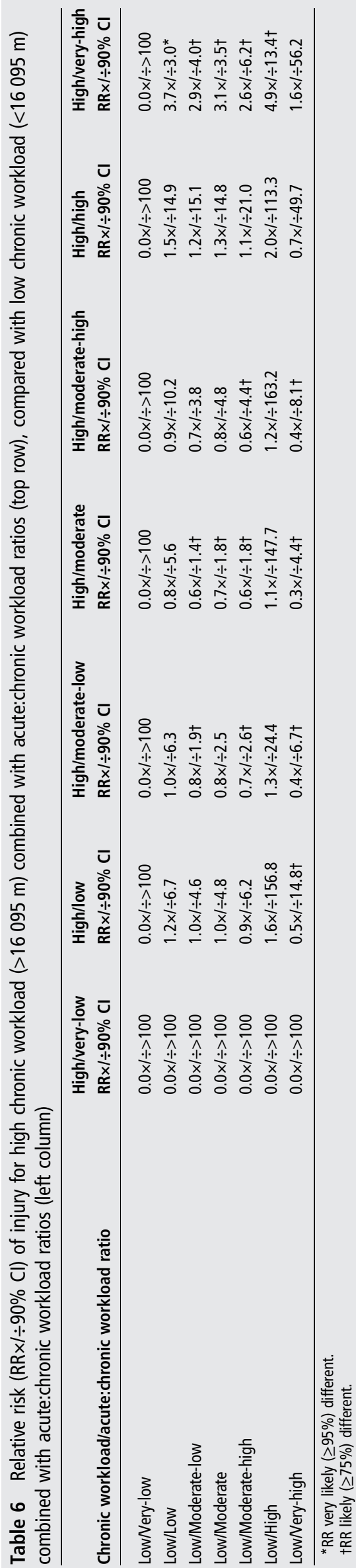

practitioners. However this study provides a method of, and threshold values for modelling acute and chronic workloads to predict the relative risk and likelihood of injury in elite rugby league players. Furthermore, the goal of conditioning athletes is to optimise performance and minimise injury risk. ${ }^{45}$ The acute: chronic workload ratio has been linked with improvements in performance in an individual sport, ${ }^{19-21}$ and according to this study and others, ${ }^{22}$ is linked with injury risk in team sports. Collectively, the aforementioned studies and the present findings endorse that monitoring acute:chronic workload ratios should be mainstream practice in elite sport. However, this is currently not the case. ${ }^{45}$

Another novel aspect of this study is the provision of threshold values that can be used to prescribe acute workload in order to obtain a high chronic workload. Specifically, acute workload can be increased to $\sim$ twofold of chronic workload without increasing injury risk in the current or subsequent week. However, if a very-high acute:chronic workload ratio ( 2) is prescribed in the current week, or maintained as an average over 2 weeks, the risk of injury is likely greater than if acute workload were increased by a ratio less than 2. Additionally, acute:chronic workload ratios as an average over 2 weeks should be monitored in comparison to whether chronic workload is high or low. Our findings suggest that increasing acute workload as an average over 2 weeks by: (1) greater than $\sim 1.5$ relative to a high chronic workload, or (2) greater than $\sim 2$ relative to a low chronic workload, will result in an increased risk of injury in elite rugby league players.

This study has demonstrated useful associations between simple distance measures and injury risk in elite rugby league players. We suspect that more information may be available if accelerations, high-speed running, and collisions were accounted for, however, accurate and reliable analysis of these variables is not possible with the GPS equipment used in this study. ${ }^{34-37}$ As such, accurate predictions of injury risk when using these variables would not be possible. ${ }^{38}$ Further research may address this limitation and expand on the knowledge we have provided, by using GPS equipment (eg, Catapult, $10 \mathrm{~Hz}$ ) that is capable of accurately and reliably measuring accelerations, high-speed running, and collisions. ${ }^{34} 3646$ Additionally, total distance covered has demonstrated a strong correlation $(\mathrm{r}=0.80)$ with session-RPE workload during high-intensity, intermittent team sport training. ${ }^{47}$ Session-RPE workload also has a strong positive correlation with non-contact injury $(r=0.82)$ and contact injury $(r=0.80)$ in rugby league. ${ }^{48}$ Session-RPE workload has been used to model acute:chronic workload ratios, which were associated with injury in elite cricket fast bowlers. ${ }^{22}$ These studies collectively suggest that although total distance does not incorporate all aspects of training, it is an appropriate measure of workload.

Although the findings of this study demonstrate that very-low, and low absolute workloads are associated with decreased injury risk, we are tentative to recommend that players are consistently exposed to these workloads. Rugby league players can be required to cover $\sim 1140 \mathrm{~m}$ during a $10 \mathrm{~min}$ period of matchplay, ${ }^{30}{ }^{31}$ and $9561 \mathrm{~m}$ in a full $80 \mathrm{~min}$ match. ${ }^{27}$ Therefore, very-low $(\sim 2500 \mathrm{~m})$ and low $(\sim 6000 \mathrm{~m})$ weekly workloads would likely result in players being underprepared for the physical demands of match-play, which may in turn increase the risk of injury.

\section{Summary and conclusion}

This is the first investigation of injury likelihoods relative to GPS derived acute and chronic workloads in elite rugby league 
players. Our findings demonstrate that the acute:chronic workload ratio provides a better prediction of injury than absolute workload in isolation. For the first time, we have investigated the influence of this workload ratio combined with high or low chronic workload-demonstrating that higher chronic workload can protect against injury when acute workload is similar to chronic workload. However, a high chronic workload, combined with large spikes in acute workload demonstrated the greatest risk of injury in this study. Our results establish that the ratio of acute workload to chronic workload should be monitored during the current week and as an average over 2 weeks relative to either a high, or low chronic workload. Finally, the findings of this study demonstrate that monitoring the comparison of acute and chronic workloads should be mainstream practice in elite sport.

\section{What are the findings?}

- The acute:chronic workload ratio is a greater predictor of injury than either acute or chronic workload separately.

- Compared with a low chronic workload, rugby league players with a high chronic workload are:

- More resistant to injury with moderate-low to moderate high acute:chronic workload ratios.

- Less resistant to injury with a very-high acute:chronic workload ratio.

- The acute:chronic workload ratio in the current week, subsequent week, and as an average over 2 weeks, is associated with increased injury risk in elite rugby league players.

\section{How might it impact clinical practice in the future?}

- Threshold values for modelling acute and chronic workloads to predict the relative risk and likelihood of sustaining an injury in elite rugby league players can be used in clinical practice.

- Total distance measured via global positioning systems can be modelled to predict injury risk.

- Clinical practice in team sports should incorporate monitoring of acute:chronic workload ratios.

- The size of an athlete's acute workload in relation to chronic workload should be monitored in the current week, and as an average over 2 weeks in comparison to either a high, or low chronic workload.

Acknowledgements Technical or equipment support for this study was not provided by any outside companies, manufacturers, or organisations. The authors would like to express their gratitude to: (1) Andrew Gray for organising and facilitating data collection for this project, (2) Nathan Pickworth and John Davey for assistance with data collection, (3) the anonymous reviewers and editor for their contribution during the peer-review process and (4) the players who participated in this study.

Contributors BTH, TJG and JAS are responsible for the concept, design, and production of this project. Injury and workload data were collected by DWL and BTH, respectively. BTH was responsible for data analysis and DWL assisted with interpreting injury data. PC revised this manuscript and provided statistical expertise.

Funding BTH was funded by a postgraduate scholarship provided by the University of Wollongong and the St. George Illawarra Dragons Rugby League Football Club.
Competing interests None declared.

Ethics approval University of Wollongong Human Ethics Committee, Ethics Number: HE12/421.

Provenance and peer review Not commissioned; externally peer reviewed.

\section{REFERENCES}

1 Dvorak J, Junge A, Derman W, et al. Injuries and illnesses of football players during the 2010 FIFA World Cup. Br J Sports Med 2011;45:626-30.

2 Gabbett TJ. Incidence of injury in semi-professional rugby league players. Br J Sports Med 2003;37:36-44.

3 Gabbett TJ. Incidence of injury in junior and senior rugby league players. Sports Med 2004;34:849-59.

4 Orhant E, Carling C, Cox A. A three-year prospective study of illness in professional soccer players. Res Sports Med 2010;18:199-204

5 Árnason Á, Sigurdsson SB, Gudmundsson A, et al. Physical fitness, injuries, and team performance in soccer. Med Sci Sports Exerc 2004;36:278-85.

6 Eirale $C$, Tol JL, Farooq A, et al. Low injury rate strongly correlates with team success in Qatari professional football. Br J Sports Med 2013;47:807-8.

7 Hägglund $M$, Waldén $M$, Magnusson $H$, et al. Injuries affect team performance negatively in professional football: an 11-year follow-up of the UEFA Champions League injury study. Br J Sports Med 2013;47:738-42.

8 Gabbett TJ. Influence of training and match intensity on injuries in rugby league. J Sports Sci 2004;22:409-17.

9 Rogalski B, Dawson B, Heasman J, et al. Training and game loads and injury risk in elite Australian footballers. J Sci Med Sport 2013;16:499-503.

10 Bartolomei S, Hoffman JR, Merni F, et al. A comparison of traditional and block periodized strength training programs in trained athletes. J Strength Cond Res 2014;28:990-7

11 Daussin F, Ponsot E, Dufour $S$, et al. Improvement of V02max, by cardiac output and oxygen extraction adaptation during intermittent versus continuous endurance training. Eur J Appl Physiol 2007;101:377-83.

12 Tønnessen E, Shalfawi SA, Haugen $\mathrm{T}$, et al. The effect of 40-m repeated sprint training on maximum sprinting speed, repeated sprint speed endurance, vertical jump, and aerobic capacity in young elite male soccer players. J Strength Cond Res 2011:25:2364-70.

13 Schoenfeld BJ, Ogborn DI, Krieger JW. Effect of repetition duration during resistance training on muscle hypertrophy: a systematic review and meta-analysis. Sports Med 2015:45:577-85

14 Gabbett TJ, Domrow N. Risk factors for injury in sub-elite rugby league players. Am J Sports Med 2005;33:428-34

15 Gabbett TJ, Ullah S, Finch C. Identifying risk factors for contact injury in professional rugby league players - Application of a frailty model for recurrent injury. J Sci Med Sport 2012;15:496-504.

16 Grant JA, Bedi A, Kurz J, et al. Ability of preseason body composition and physical fitness to predict the risk of injury in male collegiate hockey players. Sports Health 2015;7:45-51.

17 McCall A, Carling C, Nedelec M, et al. Risk factors, testing and preventative strategies for non-contact injuries in professional football: current perceptions and practices of 44 teams from various premier leagues. $\mathrm{Br} J$ Sports $\mathrm{Med}$ 2014;48:1352-7.

18 Colby MJ, Dawson B, Heasman J, et al. Accelerometer and GPS-derived running loads and injury risk in elite Australian footballers. J Strength Cond Res 2014;28:2244-52

19 Banister $E_{1}$ Calvert $T$, Savage $M$, et al. A systems model of training for athletic performance. Aust J Sport Med 1975;7:57-61.

20 Banister $E$, Calvert T. Planning for future performance: implications for long term training. Can J App/ Sport Sci 1980;5:170-6.

21 Banister E, Good P, Holman G, et al. Modeling the training response in athletes. In: Landers DM, ed. The 1984 Olympic Scientific Congress Proceedings. Sport and Elite Performers. Champaign, IL: Human Kinetics, 1986:7-23.

22 Hulin BT, Gabbett TJ, Blanch P, et al. Spikes in acute workload are associated with increased injury risk in elite cricket fast bowlers. Br J Sports Med 2014;48:708-12.

23 Cummins C, Orr R, O'Connor H, et al. Global positioning systems (GPS) and microtechnology sensors in team sports: a systematic review. Sports Med 2013:43:1025-42.

24 Johnston RD, Gabbett TJ, Jenkins DG. Influence of an intensified competition on fatigue and match performance in junior rugby league players. I Sci Med Sport 2013;16:460-5

25 Johnston RD, Gabbett TJ, Seibold AJ, et al. Influence of physical contact on neuromuscular fatigue and markers of muscle damage following small-sided games. J Sci Med Sport 2014;17:535-40.

26 Johnston RD, Gabbett TJ, Jenkins DG, et al. Influence of physical qualities on post-match fatigue in rugby league players. I Sci Med Sport 2015;18:209-13. 
27 Gabbett TJ, Jenkins DG, Abernethy B. Physical demands of professional rugby league training and competition using microtechnology. I Sci Med Sport 2012;15:80-6.

28 Gabbett TJ, Polley C, Dwyer DB, et al. Influence of field position and phase of play on the physical demands of match-play in professional rugby league forwards. J SCi Med Sport 2014;17:556-61.

29 Gabbett TJ. Influence of the opposing team on the physical demands of elite rugby league match play. J Strength Cond Res 2013;27:1629-35.

30 Hulin BT, Gabbett TJ. Activity profiles of successful and less-successful semi-elite rugby league teams. Int J Sports Med 2015;36:485-9.

31 Hulin BT, Gabbett TJ, Kearney S, et al. Physical demands of match play in successful and less-successful elite rugby league teams. Int I Sports Physiol Perform 2015;10:703-10.

32 Gabbett TJ, Ullah S. Relationship between running loads and soft-tissue injury in elite team sport athletes. J Strength Cond Res 2012;26:953-60.

33 Petersen C, Pyne P, Portus M, et al. Validity and reliability of GPS units to monitor cricket-specific movement patterns. Int I Sports Physiol Perform 2009;4:381-93.

34 Rampinini E, Alberti G, Fiorenza M, et al. Accuracy of GPS devices for measuring high-intensity running in field-based team sports. Int J Sports Med 2015;36:49-53.

35 Buchheit M, Al Haddad H, Simpson BM, et al. Monitoring accelerations with GPS in football: time to slow down? Int J Sports Physiol Perform 2014;9:442-5.

36 Johnston RJ, Watsford ML, Kelly SJ, et al. Validity and interunit reliability of $10 \mathrm{~Hz}$ and $15 \mathrm{~Hz}$ GPS units for assessing athlete movement demands. J Strength Cond Res 2014;28:1649-55.

37 Gabbett TJ. Quantifying the physical demands of collision sports: does microsensor technology measure what it claims to measure? I Strength Cond Res 2013;27:2319-22.
38 Bahr R, Holme I. Risk factors for sports injuries - a methodological approach. Br J Sports Med 2003;37:384-92.

39 King DA, Hume PA, Milburn PD, et al. Match and training injuries in rugby league: a review of published studies. Sports Med 2010;40:163-78.

40 Economos CD, Hyatt RR, Goldberg JP, et al. A community intervention reduces BMI z-score in children: shape up Somerville first year results. Obesity 2007; 15:1325-36.

41 Ma J, Siminoski K, Alos N, et al. The choice of normative paediatric reference database changes spine bone mineral density Z-scores but not the relationship of bone mineral density with prevalent vertebral fractures. J Clin Endocrinol Metab 2015;100:1018-27.

42 Hopkins WG. A spreadsheet for deriving a confidence interval, mechanistic inference and clinical inference from a P value. Sportscience. 2007;11:16-20.

43 Batterham AM, Hopkins WG. Making meaningful inferences about magnitudes. Int J Sports Physiol Perform 2006;1:50-7.

44 Hopkins WG, Marshall SW, Batterham AM, et al. Progressive statistics for studies in sports medicine and exercise science. Med Sci Sports Exerc 2009;41:3-12.

45 Herring SA, Bergfeld JA, Boyajian-O'Neill L, et al. The physician and strength and conditioning of athletes for sports: a consensus statement. Med Sci Sports Exer 2015;47:440-5

46 Gabbett TJ, Jenkins DG, Abernethy B. Physical collisions and injury during professional rugby league skills training. J Sci Med Sport 2010;13:578-83.

47 Scott BR, Lockie RG, Knight TJ, et al. A comparison of methods to quantify the in-season training load of professional soccer players. Int I Sports Physiol Perform 2013:195-202.

48 Gabbett TJ, Jenkins DG. Relationship between training load and injury in professional rugby league players. J Sci Med Sport 2011;14:204-9. 